\title{
Realized envrionmental values of Envrionmental Fallow policy measure
}

\author{
Irina Herzon $^{1 *}$, Marjaana Toivonen ${ }^{1}$, Juha Helenius $^{1}$, Chloe Swiderski $^{2}$ \\ ${ }^{1}$ Department of Agricultural Sciences, P.O. Box 27, FI-00014 University of Helsinki, Finland \\ ${ }^{2}$ ENITA de Bordeaux 1 cours du Gal De Gaulle CS 4020133175 Gradignan Cedex \\ *Corresponding author. Tel.: +3859405330946; fax: + 358919158582. E-mail address: \\ herzon@mappi.helsinki.fi
}

\begin{abstract}
A novel agri-environment scheme for Environmental Fallow (EF) was introduced in Finland to replace a former obligatory CAP set-aside. Though potentially highly valuable, the ability of the current scheme for delivering the stated objectives of water protection, biodiversity, and soil state is yet to be confirmed. The presentation evaluates the role of the scheme for protection of surface waters and biodiversity based on data from the farmer interviews, field data on vegetation, and land-use register for the regions of Uusimaa, Pohjois-Pohjanmaa and Pirkanmaa.

In 2010, over $7 \%$ of the agricultural utilized area was enrolled under the scheme with four types of fields: long-term grasslands, and fields sown with meadow plants, game crops or landscape flowers. The scheme has been highly popular among farmers but requires agronomic development of the options to reduce establishment failure, and optimise management for the best environmental output with the least agronomic problems. The potential of the scheme to protect surface waters is marginal since only $10 \%$ of EFs is situated near the water courses. The option of fallowing by establishing grassland, or by enrolling existing low productive grassland, was the most popular type of EF. The most biologically valuable meadow type remains rare, and the desired vegetation composition is non stable. The vegetation composition of the EF is more diverse than that under the former set-aside and also differs from that of other non-cropped biotopes such as margins and semi-natural grasslands. Plant species diversity correlated negatively with the reported fertility level of the parcels and therefore establishing grassland and meadow fallows on the least productive parcels is ecologically justified. However, possible targeting of the options according to the landscape setting should be investigated. At the current level, the scheme has succeeded to reverse the fallowing area to its state during the EU set-aside period. However, potential long-term efficiency of the current scheme is likely to be compromised by its untargeted and unbinding nature, and existing agronomic challenges in "sowing for nature". Without a minimum required area, the scheme totally depends on the current and forecasted profit margin.
\end{abstract}

\section{Keywords}

agricultural runoff; agri-environmental programme; Common Agricultural Policy; set-aside; vegetation 


\section{Introduction}

A considerable detrimental impact on the ecological state of agricultural ecosystems caused by intensive production of food, fiber and, increasingly, biofuels in Europe has been well documented (Stoate et al., 2009). The CAP set-aside obligation as a political measure to reduce production volumes has had also positive environmental side-effects such as reduction in nurtient losses, enhancement of farmland biodiversity, and associated ecosystem services (ibid). The set-aside requirement was abolished in 2008 and this led to the legitimate concerns for the loss of such benefits. Finland is one of the few countries in the EU that replaced set-aside with a targeted agri-environment scheme for environmental fallow (EF) already in 2009 (Herzon et al., 2010). It is arguably the single most important subsidy scheme targeted at natural values of ordinary agricultural landscapes and the one currently most preferred by farmers. These and a large budget spending on this scheme make it imperative to investigate the actual environmental outcomes and explore possibilities for its further development. Though potentially highly valuable, the ability of the current scheme for delivering the stated objectives of water protection, biodiversity, and soil state need to be confirmed.

The Finnish scheme includes two main types of EF: 1) long-term grassland for protection of soil from erosion and nutrient leaching, improvement in soil structure, and reduction in use of plant protection chemicals, with some benefits also for biodiversity; and 2) biodiversity field, including meadow, game and landscape fields, designed specifically to provide resources for wildlife species as well as landscape amenity. Here we evaluate the role of the scheme in protection of surface waters and biodiversity based on data from the farmer interviews, field data on vegetation, and land-use register. Possibilities of developing the scheme as well as remaining issues for further research are discussed.

\section{Data and Methods}

We assumed that the fallow fields situated by the water bodies (lakes, sea shore and major ditches) have a direct buffering effect in protecting watercourses from agricultural runoff, while fields elsewhere in the landscape, only indirect (through no-input management). We categorized the fallows according to the distance between these fields and watercourses: i) fields by watercourses; ii) fields situated at least 50 meters from watercourses, and iii) fields more than 50 meters from watercourses. The distribution of fallows by the three classes was compared to that of the cultivated fields in the respective region. Digitised data on the water courses and fields came from the Land Use Register and the Information Centre of the Ministry of Agriculture and Forestry.

As a measure of biodiversity value, we used species richness and composition of vascular plants. The data were collected from three regions in Finland different in their geographical position and character of agricultural production, Uusimaa, Pohjois-Pohjanmaa, and Pirkanmaa. Within each region, farms were selected randomly but within a $100-\mathrm{km}$ circle from the regional centre with at least five EF fields in 2009. The survey fields were selected according to the ratio of 3:1:1:3 representing the four prescribed types (grassland, game, landscape, and meadow fields). The ratio was based on the assumption that the grassland and meadow types would be most variable in vegetation. The fields were chosen to represent respective regional variations in sizes of EFs and placement in respect to the forests. A total of 215 parcels were surveyed (Table 1).

Table 1. The surveys sample sizes by regions and field types.

\begin{tabular}{lcccc}
\hline Fallow type & Uusimaa & $\begin{array}{c}\text { Pohjois- } \\
\text { Pohjanmaa }\end{array}$ & Pirkanmaa & Total \\
\hline Grass & 46 & 22 & 22 & 90 \\
Game field & 10 & 7 & 7 & 24 \\
Landscape field & 10 & 7 & 7 & 24 \\
Meadow field & 33 & 22 & 22 & 77 \\
Total & 99 & 58 & 58 & 215 \\
\hline
\end{tabular}


Vegetation surveys were conducted in Uusimaa and Pohjois-Pohjanmaa in summer of 2010 and in Pirkanmaa in summer 2011 between end of June and mid-August. One to four lines of 1,0 x 12,5 metres were placed within each field depending on its size. At each line, the following parameters were measured: vegetation height and density, coverage of grasses, coverage of the sown species, area of bare soil, cover of the species and species groups, signs of mowing, mowing and collection of biomass, and grazing. Covers of individual species and species groups were estimated visually on the 9-grade logarithmic scale. All fieldworkers underwent training in the method.

The owners of the surveyed farms were interviewed in person and by telephone about the management issues and the experienced and perceived benefits and problems of the scheme.

Firstly, we modelled the species richness of all plots in respect to the region, type of the fallow field, and their interaction. Since vegetation of game and landscape fallows resembles an arable field and it is grassland and meadow fallows that have potential to develop semi-natural swards of a high biodiversity value, we next modelled species richness only of grassland and meadow parcels in respect to region and type, and also such covariates as parcel area, establishment year, vegetation structure, and its variability. The structure was represented as gradient derived from Principle Component Analysis of the parameters describing the vegetation character (height, density, and amount of bare ground). Variability in vegetation height and density was calculated as a variance over all the measures for each field. Finally, for grassland and meadow fallows with available data, we looked at soil fertility, expressed as a relative difference between the farmer's information on the crop yield from the preceding year and the average regional yield of a respective ELY-centre ( $n=23$, all sown in 2008 and 2009).

In order to evaluate the contribution of EFs to the existing vegetation diversity in the agricultural landscape, we compared the fallow vegetation with that of the other non-cropped types: margins (including buffer strips), meadows, and semi-natural pastures, as well as a sample of production grassland fields. The data on the semi-natural areas were obtained from MYTVAS-programme, in which the same field method and estimate grade of the species coverages were used. The only difference was that in the fallow survey the total sample area of $50-\mathrm{m}^{2}$ was split into four sub-transects while in MYTVAS one 50$\mathrm{m}^{2}$ transect was used. To reduce the potential bias stemming from this and an unknown variation in the coverage estimates made by different observers, we pooled the neighbouring classes into six categories. We treated some infrequent gramineous species at level of genus to reduce potential identification mistakes. The comparison was run only on data from the same year and region (2010 and South Finland) and for fallow fields with four lines (same survey area per sample as in MYTVAS). Additionally, five production grasslands sampled during the fallow project were included into ordination.

The geo-referenced analysis was run in MapInfo Professional (version 10, Pitney Bowes Software Inc., Troy, NY, USA) and modelling in PASW Statistics (version 17, SPSS Inc., USA). Community analysis was done in NMS-ordination (Nonmetric Multidimensional Scaling) (McCune and Grace 2002) in PC-ORD (version 5, MjM Software, USA).

\section{Results}

The EFs currently occupy $6.6 \%$ of the agricultural area (TIKE, 2011). In 2010, around $80 \%$ of the EFs were of the grassland type. The EF parcels spread fairly evenly across all provinces (ibid).

Concerning the role of EFs in protection of watercourses from agricultural runoff, only $9-12 \%$ of all the fallows in the studied regions are situated either by the watercourses or within $50 \mathrm{~m}$ from them (about $80 \%$ of these are of the grassland type), and $40 \%$ of the fallows border major ditches. The respective percentages for the cultivated fields are $10-25 \%$ for the watercourses and $50 \%$ for the major ditches.

The total number of registered species and species groups was 215 . There were some consistent differences in the number of species among the fallow types and the regions (Figure 1). Meadow fallows are characterised by the highest species-richness of vascular plant while game fields by the lowest. Fallows in Pohjois-Pohjamaa were poorest in species. The final model for grassland and meadow fields retained fallow type (meadows more species-rich than grasslands), region (the highest species richness in 
Pirkanmaa and the lowest in Pohjois-Pohjanmaa), area (positive relation), vegetation structure (negative), variation in height (positive), and establishment year (negative) (Table 3).

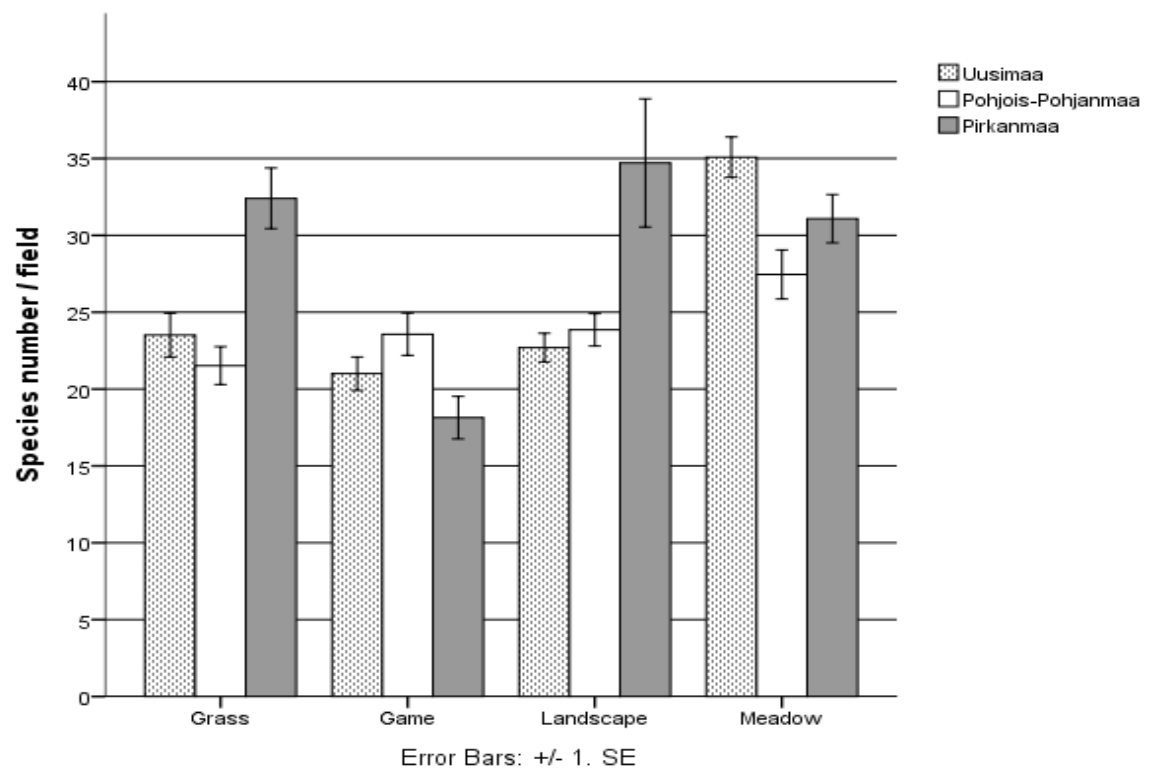

Figure 1. Number of species and species groups in environmental fallows of four types across three Finnish regions

Plant species diversity in grassland and meadow fallows correlated negatively with the reported fertility levels (Pearson $\mathrm{r}-0,438, \mathrm{P}=0,018$ one-tailed; $\mathrm{n}=23$ ). There was a positive correlation between the fertility level and the vegetation structure towards dense and high swards (Pearson $\mathrm{r}-0,499, \mathrm{P}=0,008$ one-tailed; $\mathrm{n}=23$ ).

Table 3. The final model for the number of plant species in grassland and meadow fallows.

\begin{tabular}{lrr}
\hline Parameter & Estimate & \multicolumn{1}{c}{$\mathrm{P}$} \\
\hline Intercept $^{2}$ & 618,215 & $* *$ \\
Grassland fallow $^{\mathrm{a}}$ & $-8,402$ & $* * *$ \\
Uusimaa $^{\mathrm{b}}$ & $-3,508$ & $*$ \\
Pohjois-Pohjanmaa $^{\mathrm{b}}$ & $-7,349$ & $* * *$ \\
Area & 1,801 & $* *$ \\
Vegetation Structure $^{*}$ & $-1,726$ & $*$ \\
Height Variation $_{\text {Establishment Year }}$ & 0,003 & $*$ \\
\hline
\end{tabular}

a as compared to meadow type; ${ }^{b}$ as compared to Pirkanmaa

The compositional analysis of the fallow vegetation and that of the semi-natural elements demonstrated that i) vegetation composition of EFs only partly overlap with that of the semi-natural areas, and ii) the fallow types differ among themselves. The game fallows have the most specific vegetation (a mixed crop stand of cereals, Pisum sativum and Brassicaceae, and abundant annual weeds) and were placed far apart from the other plots. For the ease of the view, they have been removed from Fig. 1. The next most distinct vegetation is that of meadow and landscape fields: they include sown species not found in either crop fields or semi-natural areas (e.g. Phacelia tanacetifolia), and abundant annual "weeds" of arable fields. The grassland fallow fields have the most diverse composition of swards: some are close to 
the production grasslands and characterised by grass-dominated swards with sown legumes (Trifolium spp.) and annual "weeds" of arable fields, e.g. Galeopsis spp.). Some grassland fallows resemble seminatural areas and are characterised by vegetation of a long-term succession that includes perennial forbs, also typical of forest edges (e.g. Geranium sylvaticum).

The most frequent species on the grassland fields were Ranunculus repens and Phleum pratense, on the game fallows cereals and Persicaria lapathifolia, on the landscape fields Phacelia tanacetifolia, and on the meadows Leucanthemum vulgare and Elymus repens. The species with the highest coverage were $P$. pratense and $E$. repens on grasslands, cereals and $P$. lapathifolia on the game fallows, Trifolium pratense and $P$. pratense on the landscape, and $P$. pratense and Festuca $s p$. on the meadows. Over all fallow types, E. repens was both the most frequent and abundant species. Species nationally classified as rare or endangered have been registered only on nine fallow fields.

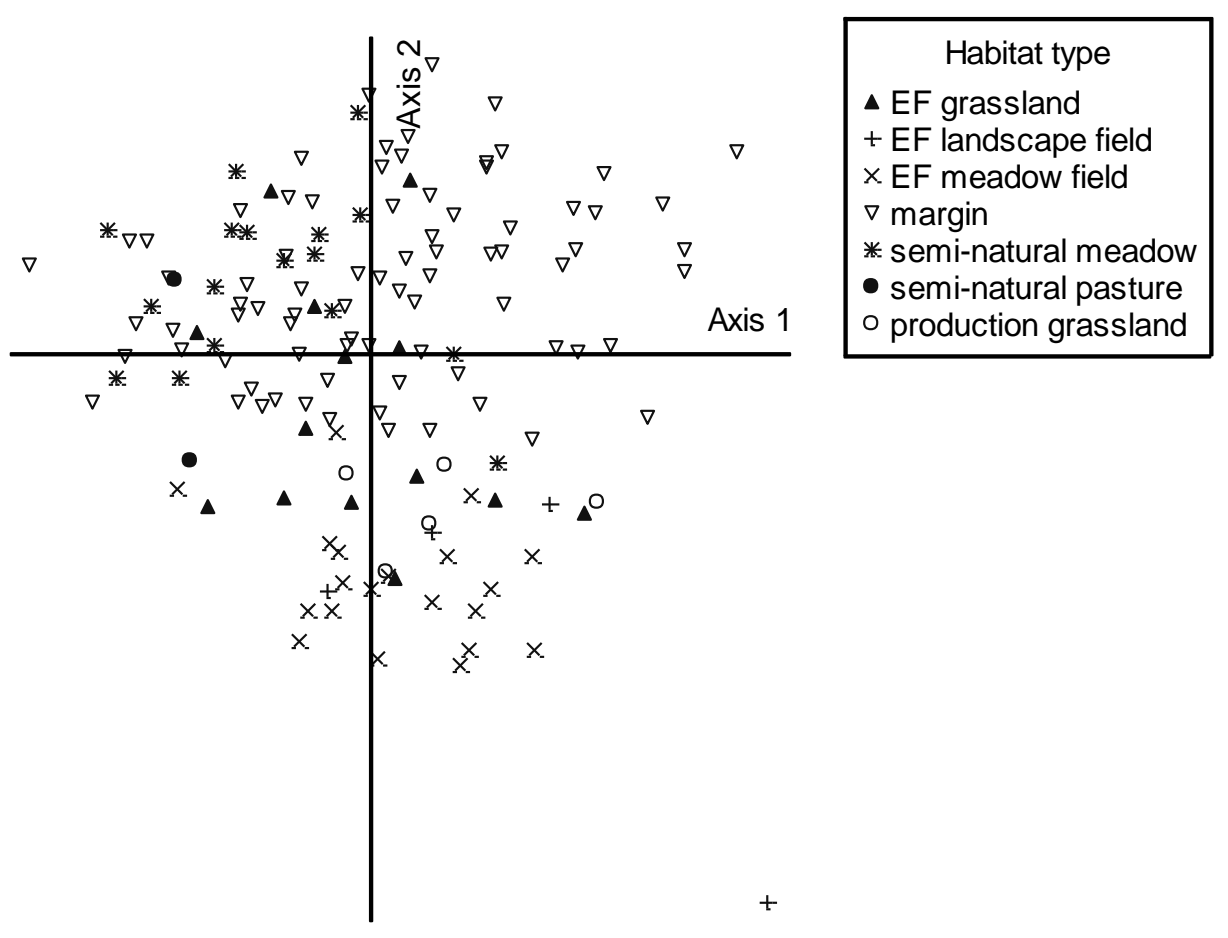

Figure 2. Biplot of fallow fields derived from their vegetation composition.

Higher numbers of species were accounted in semi-natural meadows and meadow fallows than in the other biotopes and fallows types (ANOVA, $\mathrm{p}<0,001$; LSD Post-Hoc testi, $\mathrm{p}<0,01$ ). Differences among other types were not statistically significant.

Information pertaining to the fallow establishment and management came from 57 farmers corresponding to 189 parcels. The majority of the fields have been established in 2009 in response to the novel subsidy, especially biodiversity fields, though about one third of grassland fallows have continued from the long-term set-asides. Among the benefits of fallows, farmers most often mentioned support of game populations, enhancement of soil fertility, protection of waters, and landscape values. One third also observed increased numbers of pollinating insects and farmland birds. Among the challenges, an increased abundance of weeds was by far the most often cited issue. Also difficulties in obtaining suitable seed mixtures, their cost, and a short-term survival of many sown flowering plants were discussed. 


\section{Discussion}

The new policy support had a notable effect on the amount of fallow fields re-established in the landscape after their abolition in 2008. Especially novel fallow types of meadows have all been created due to the support scheme.

Only a limited number of fallow fields were established specifically close to the surface waters and therefore directly contribute to the buffering of the surface waters from the nutrient runoff. Their impact is likely to be only indirect through reduction in agricultural inputs in the landscape. The management of the current fallow fields should therefore be tailored to achievement of the other (potential) environmental benefits, such as biodiversity and soil fertility.

The novel fallow scheme considerable contributed to the heterogeneity in agricultural landscape since the fallow vegetation has mostly distinct composition in comparison to that of the existing seminatural areas, and the species diversity of the meadow type was comparable to that of the most speciesrich semi-natural biotope. Presence of such fallows in the landscape boosts heterogeneity over the landscape which was suggested to be the key issue in biodiversity of agricultural environments (Benton et al., 2003). Meadow fields combine the variety of sown (meadow) plants and, due to the inclusion of grasses with poor competitive ability, also species germinating from the seed-bank (Kuussaari et al. 2011). Creating other fallow types than rotational grassland (mostly resembling production grassland fields) and especially meadows should be supported with sufficiently high premium since they entail high establishment costs and novel agronomic challenges. Vegetation of game and landscape fields is generally homogenous since it is sown for specific purposes such as to provide food for game or an attractive colourful sward. Their additional value for other purposes related to nature management is poorly known. The grassland fallows considerably vary in terms of species richness and composition because they include both fields sown freshly with a conventional mixture capable of suppressing unsown species, and long-term fallows set aside from production in the preceding decades. These two extreme types have a different biodiversity value and are subjected to different management regime, and therefore should be treated separately in terms of support.

Retaining long-tem fallows as environmental fallow should be encouraged since the age of fallow also related to the species diversity (vf. Critchley \& Fowbert 2000, Steffan-Dewenter \& Tscharntke 1997). Also only long-term fallows on poor soils have a potential to contribute to conservation of endangered plant species. Otherwise, rare species seldom survive in former agricultural fields with relatively high nutrient status and history of frequent disturbance (Critchley \& Fowbert 2000, Firbank et al. 2003). However, our results for rare species should be regarded as conservative hence the survey was restricted to the sample lines and infrequent species may have remained unregistered. There was a considerable variation among the old fallows and therefore management should be tailored to retention and enhancement of the biodiversity value (e.g., late summer mowing and removal of biomass; extensive grazing). Only few fallows studied here have been managed appropriately.

Establishing meadow and grassland fallows on the least fertile parcels is justified from both production and ecological sides. Adverse impact of high fertility levels on vegetation diversity in seminatural biotopes is well established (for example, Klejn \& Snoeijing 1997). Finally, fallowing of portion of fields should be supported across all regions due to the variation in vegetation resulting from considerable geographical and climatic differences (Kivinen et al. 2006), and dispersal needs for organisms associated with farmland.

Rather than preservation of national biodiversity, fallow vegetation is likely to contribute to the provisioning of ecosystem services by the species capable of persisting within the conventional agricultural landscapes (Kleijn et al., 2011). Among the potential servicers are pollination by native pollinators, biological control, improvement of soil structure, landscape amenity and recreation (through resources for game and birds). On the other hand, there are clear dis-services (cit Zhang et al., 2007) coming from the fallow fields, the most notable of which is increase in weeds. This combined with the restriction on using herbicides for the fallow termination sets a serious agronomic challenge for incorporating biodiversity fallows into production landscapes. 


\section{Conclusion}

The preliminary results on the contribution of the EF to the environmental objectives justify the biodiversity value of the fallows in the agrolandscapes, but not protection of surface waters. Area-wise the EF scheme has substituted the former set-aside on national level and is a step forward since the fallow includes more diverse types of vegetation than set-aside. At the current level EF scheme has succeeded in reverting the fallowing area to a half of its "set-aside" state. However, future of the established network is uncertain since the scheme is not binding, and therefore depends on the current and forecasted profit margin. Already in year 2011, there has been 7\% decline in the national coverage. A recent proposal of EU Commission to introduce a minimum requirement for Ecological Focus Area, that would include all elements of a fallow type, will be capable of securing the environmental benefits over the whole agricultural landscape. Regional and landscape-level targeting may be needed to achieve multiple benefits (for example, proximity to water courses, favouring biodiversity option fallow types in the landscape with abundant production grasslands). The current challenges of establishing and managing such novel "crops", and especially meadow fields, should be addressed through targeted research on the optimised placement in regard of the landscape (e.g. availability of grassland, landscape openness), best seed mixtures for different soils and level of sun exposure, and agrotechnical practices for achieving maximum environmental output with minimal agronomic problems for the surrounding and subsequent crops. Value of fields for other taxa, especially those providing ecosystem services important for production should be investigated.

\section{References}

Benton, T. G., Vickery, J. A. \& Wilson, J. D. 2003. Farmland biodiversity: is habitat heterogeneity the key? TREE 18: $182-188$.

Critchley, C. N. R. \& Fowbert, J. A. 2000. Development of vegetation on set-aside land for up to nine years from a national perspective. Agric. Ecosys. Environ. 79: 159-174.

Firbank, L. G., Smart, S. M., Crabb, J., Critchley, C. N. R., Fowbert, J. W., Fuller, R. J., Gladders, P., Green, D. B., Henderson, I. \& Hill, M. O. 2003. Agronomic and ecological costs and benefits of set-aside in England. Agric. Ecosys. Environ. 95: 73-85.

Herzon, I., Helenius, J., Kuussaari, M., Mäkinen, T. \& Tiainen, J. 2010. Agri-environmental programme in Finland serving biodiversity: working forward. Aspects of Applied Biology 100: 261-269.

Kivinen, S., Luoto, M., Kuussaari, M. \& Helenius J. 2006. Multi-species richness of boreal agricultural landscapes: effects of climate, biotope, soil and geographical location. J. Biogeography 33: 862-875.

Kleijn, D. \& Snoeijing, I. J. 1997. Field boundary vegetation and the effects of agro-chemical drift: botanical change caused by low levels of herbicides and fertilizer. J. Appl. Ecology 34: 1413-1425.

Kuussaari, M., Hyvönen, T. \& Härmä, O. 2011. Pollinator insects benefit from rotational fallows. Agric. Ecosys. Environ. 143: 28-36.

Steffan-Dewenter, I. \& Tscharntke, T. 1997. Early succession of butterfly and plant communities on set aside fields. Oecologia 109: 294-302.

Stoate, C., Baldi, A., Beja, P., Boatman, N., Herzon, I., van Doorn, A., de Snoo, G., Rakosy, L. \& Ramwell, C. 2009. Ecological impacts of early 21 st century agricultural change in Europe - A review. J. Environ. Management 91: $22-46$.

Tike 2011. Utilized agricultural area in 2011 - forecast 21.6.2011. http://www.maataloustilastot.fi/kaytossa-olevamaatalousmaa. Matilda Agricultural Statistics. Last accessed 20.11.2011.

Zhang, W., Ricketts, T.H., Kremen, C., Carney, K. \& Swinton, S.M. 2007. Ecosystem services and dis-services to agriculture. Ecol. Econ. 64: 253-260. 